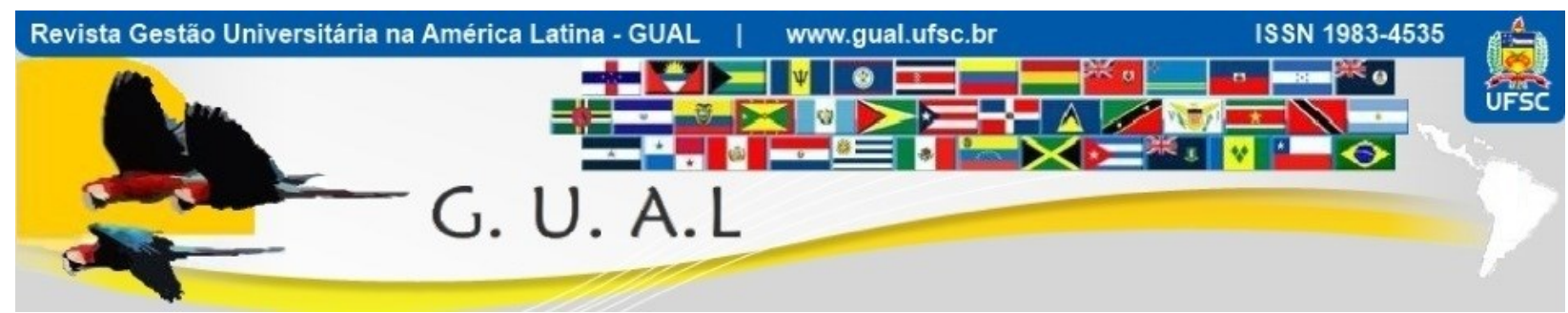

DOI: http://dx.doi.org/10.5007/1983-4535.2015v8n1p1

\title{
EMPRESAS JUNIORES: O PROCESSO DE INSTITUCIONALIZAÇÃO EM UNIVERSIDADES PÚBLICAS DO CEARÁ
}

\section{JUNIOR ENTERPRISE: THE PROCESS OF INSTITUTIONALIZATION IN PUBLIC UNIVERSITIES OF CEARÁ}

Emanuel Dheison dos Santos Penha, Mestrando Universidade Federal do Ceará - UFC emanueldheison@hotmail.com

Mariana de Melo Alexandre, Mestranda Universidade Federal do Ceará - UFC marimalexandre@yahoo.com.br

Augusto Cézar de Aquino Cabral, Doutor Universidade Federal do Ceará - UFC cabral@ufc.br

Sandra Maria dos Santos, Doutora Universidade Federal do Ceará - UFC smsantos@ufc.br

Maria Naiula Monteiro Pessoa, Doutora Universidade Federal do Ceará - UFC naiula@ufc.br

Recebido em 02/agosto/2013

Aprovado em 15/dezembro/2014

Sistema de Avaliação: Double Blind Review 


\title{
RESUMO
}

Essa pesquisa tem por objetivo investigar o processo de institucionalização das empresas juniores (EJs) das universidades públicas do Ceará, tendo como modelo o processo de institucionalização de Tolbert e Zucker (1999) em suas três fases: habituação, objetificação e sedimentação. A pesquisa, além de ser bibliográfica, classifica-se como um estudo descritivo, de natureza qualitativa e quantitativa. O estudo foi realizado em 10 EJs do Ceará. Na coleta de dados, foram utilizados questionários, aplicados junto aos membros, e entrevistas com os presidentes das EJs. Os resultados apontam que a principal motivação para o surgimento das EJs nas universidades públicas do Ceará foi a necessidade de aliar a teoria à prática. Os principais atores no processo destas entidades foram os alunos. Não há grupos de resistência, porém há uma ameaça em relação à perspectiva de continuidade devido a alta rotatividade na EJ. As EJs estão entre as fases de objetificação e sedimentação e que as características isomórficas, entre EJs, estão relacionadas ao compartilhamento das boas práticas de gestão.

Palavras-chave: Empresa Júnior. Instituicionalização. Universidade Públicas.

\begin{abstract}
This research aims to investigate the process of institutionalization of Junior Enterprises (JEs) of the public universities of Ceará, according to the model of institutionalization of Tolbert and Zucker (1999) in its three phases: habituation, objectification and sedimentation. This research is bibliographic, being classified as a descriptive study of qualitative and quantitative nature. The study was conducted in 10 JEs of Ceará. During data collection, questionnaires administered with members, and interviews with the presidents of the JEs were used. The results show that the main reason for the emergence of IOs in public universities of Ceará was the need to combine theory with practice, the main actors in the process of these entities were students. No resistance groups, but there is a threat at the prospect of continuity due to high turnover in JEs. The JEs are among the phases of objectification and sedimentation and isomorphic characteristics, among JEs, are related to the sharing of best management practices.
\end{abstract}

Keywords: Junior Enterprise. Institutionalization. Public University. 


\section{INTRODUÇÃO}

A universidade é baseada no tripé: ensino, pesquisa e extensão. $\mathrm{O}$ ensino universitário busca transmitir conhecimento científico, formando, assim, profissionais de nível superior. A pesquisa está relacionada à produção de novos conhecimentos e a ampliação do saber (SANTOS, 2012). Já a extensão está ligada à integração ensino-pesquisa, teoria e prática, “em que a comunidade deixa de ser passiva no recebimento das informações/conhecimentos transmitidos pela universidade e passa a ser, participativa, crítica e construtora dos possíveis modos de organização e cidadania" (JEZINE, 2004, p.03).

Essa perspectiva metodológica de ensino das Universidades vai ao encontro da pesquisa do NTL Institute for Applied Behavioral Science (apud MEISTER, 1999) que analisou diferentes metodologias de ensino e verificou qual a taxa de retenção do conhecimento de cada método. O resultado demonstrou que o índice de retenção do conhecimento de pessoas que põem em prática os conhecimentos adquiridos é de $75 \%$, enquanto o índice de retenção de pessoas que apenas assistem às palestras expositivas é de $5 \%$ e palestras com recursos audiovisuais é de $20 \%$. Isso denota que o fato de aliar teoria e prática potencializa a absorção de conhecimento por parte dos alunos.

Dentre as diversas ações de extensão da Universidade, destaca-se a empresa júnior (EJ) que, segundo Matos (1997), é uma associação civil, sem fins lucrativos, constituída e gerida exclusivamente por alunos de graduação, tendo como objetivo principal propiciar aos estudantes a oportunidade de aplicar e aprimorar os conhecimentos teóricos adquiridos durante seu curso. No Brasil, segundo o censo de 2012 da Brasil Júnior, 7.775 alunos de graduação participam de EJ, em um total de 365 empresas juniores (EJs).

Porém, apesar da relevância do tema, os estudos vistos até o momento retratam a EJ sob a ótica da aprendizagem (ZILIOTTO, BERT, 2012; VAZQUEZ, SILVA, NATIVIDADE et al., 2012; BATISTA, BITENCOURT, SILVA et al., 2010), práticas gerenciais (BETTONI, SILVEIRA, SILVA, 2011), competências (LIMA，CANTAROTTI, 2010; JÚNIOR, MARQUES, 2012), empreendedorismo (COSTA, LIMA, BARROS et al., 2010; DALMORO, TRINDADE, VISENTINI et al., 2008) e outros, tendo como objeto de estudo os alunos.

Além disso, percebe-se que os estudos sobre EJ no Brasil são recentes, apesar de, segundo Matos (1997), o conceito EJ começar a ser aplicado no Brasil em 1989. No entanto, os estudos à luz da Teoria Institucional são restritos, em especial sob o aspecto do processo de 
institucionalização. Dada à importância das EJs no contexto da universidade, é relevante verificar que fatores contribuíram para o seu surgimento; quais os principais atores sociais e suas influências; quais são os impactos positivos da sua atuação; a estruturação, a formalização e sistematização de suas atividades e se a EJs possuem perspectivas de continuidade. Ou seja, maturidade e institucionalização.

Uma estrutura institucionalizada é considerada pelos atores de um grupo social como eficaz e necessária. O processo de institucionalização é central na criação e perpetuação de grupos sociais duradouros. Tolbert e Zucker (1998) propuseram um modelo constituído de três estágios: habitualização, objetificação e sedimentação, que é a base dessa pesquisa.

Buscando explorar tal questão, esse trabalho buscou responder a seguinte pergunta: como se dá o processo de institucionalização das empresas juniores das universidades públicas do Ceará? A partir desse questionamento, surgem os seguintes pressupostos: 1) $\mathrm{O}$ principal fator que motivou o surgimento e desenvolvimento das EJs nas universidades públicas do Ceará foi a necessidade de aliar a teoria à prática; 2) Os principais atores sociais no processo de institucionalização das EJs das universidades públicas do Ceará são os alunos; 3) Em relação aos impactos positivos, percebe-se que a maior contribuição das EJs é o aumento da aprendizagem interdisciplinar e voltada para o mercado, não há grupos de resistência e os principais interessados são os alunos, em relação à perspectiva de continuidade, esse é um dos principais problemas devido ao alto grau de rotatividade dos membros das EJs; 4) As EJs estão no estágio de sedimentação e 5) As características isomórficas estão relacionadas ao compartilhamento das boas práticas de gestão.

A fim de responder à questão de pesquisa, tem-se como objetivo geral: investigar o processo de institucionalização das empresas juniores das universidades públicas do Ceará. Este objetivo desdobra-se em: 1) Identificar os principais fatores que motivaram o surgimento e desenvolvimento das empresas juniores das universidades públicas do Ceará; 2) Identificar os principais atores sociais, suas relações e influências, no processo de institucionalização das empresas juniores das universidades públicas do Ceará; 3) Verificar os impactos positivos, os grupos de interesse e resistência e a perspectiva de continuidade das EJs das universidades públicas do Ceará; 4) Identificar o estágio de institucionalização das empresas juniores das universidades públicas do Ceará e 5) Averiguar quais são as características isomórficas das empresas juniores das universidades públicas do Ceará. 
Quanto à abordagem, em alinhamento à taxionomia proposta por Sampieri, Collado e Lucio (2013), a metodologia dessa pesquisa se caracteriza por um modelo multimodal. Quanto aos fins, trata-se de uma pesquisa descritiva. Quanto aos meios, é uma pesquisa bibliográfica e de campo.

\section{TEORIA INSTITUCIONAL}

Nessa seção, aborda-se, inicialmente, como diversos autores conceituam institucionalização. Em seguida, será tratado o processo de institucionalização na visão autoras Tolbert e Zucker, que é subdividido em habitualização, objetificação e sedimentação. $\mathrm{Na}$ última parte, aborda-se o tema isomorfismo institucional.

\subsection{FUNDAMENTOS DA TEORIA INSTITUCIONAL}

O desenvolvimento do ser humano se dá à medida que ele interage tanto com o ambiente natural como com o cultural e social específico do seu meio, sendo assim, direcionado pela sociedade. Observa-se que a institucionalização tem sua origem na atividade humana, pois tal atividade está sujeita a habituação, e a ação repetida com frequência molda um padrão, que pode ser executado novamente no futuro. $\mathrm{O}$ pano de fundo da atividade tornada hábito dá origem a um primeiro plano de deliberação e inovação (BERGER; LUCKMANN, 1998).

Até a década de 1940, os estudos tratavam as organizações apenas como aspectos de problemas sociais não se focavam as organizações enquanto organizações. Elas eram vistas como sistemas fechados, independentes do ambiente na qual estavam inseridas. A partir do trabalho de Robert Merton, no fim da década de 1940, as organizações passaram a ser reconhecidas como fenômenos sociais, dignas de estudos próprios. Os pesquisadores perceberam que as organizações eram afetadas pelo ambiente externo (TOLBERT; ZUCKER, 1998; QUINELLO, 2007).

$\mathrm{Na}$ administração, o estudo sobre a Teoria Institucional constitui-se um campo incipiente, e é resultado da convergência de influências teóricas advindas da ciência política, da sociologia e da economia (MACHADO-DA-SILVA; GONÇALVES, 1999). Para North (1990, p. 3), as instituições são as regras do jogo de uma sociedade, são as restrições humanamente inventadas que moldam a interação humana. $\mathrm{O}$ autor afirma ainda que, para o desenvolvimento de uma nação, a evolução institucional é mais relevante do que avanços 
tecnológicos ou acumulação de capital. Meyer e Rowan (1977) defendem que muitas estruturas organizacionais formais surgem como reflexos de regras institucionais racionalizadas. A elaboração de tais regras em estados modernos resulta na expansão e no aumento da complexidade das estruturas organizacionais formais. Regras institucionais funcionam como mitos que as organizações incorporam, ganhando legitimidade, recursos, estabilidade e perspectivas de sobrevivência.

A institucionalização não é algo que se desenvolve de modo instantâneo, pois conforme a definição de Selznick (1971, apud QUINELLO, 2007) “institucionalização é um processo. É algo que acontece com o passar do tempo, refletindo sua história particular, o pessoal que nela trabalhou, os grupos que englobam com os diversos interesses que criaram, e a maneira como se adaptou ao seu ambiente." É um processo fundamental no desenvolvimento e na perpetuação de grupos sociais duradouros e de ações tornadas habituais e aceitas (QUINELLO, 2007). As instituições implicam historicidade (BERGER; LUCKMANN, 1998). Para Tolbert e Zucker (1983) Institucionalização refere-se ao processo através do qual os componentes da estrutura formal tornam-se amplamente aceitos, tanto adequados como necessários, e servem para organizações se legitimarem. Fundamentalmente, o processo é uma mudança social.

Emergiram da Teoria Institucional dois movimentos: o velho institucionalismo, que surgiu a partir dos anos 1950, com os trabalhos de Selznick, onde, conforme Quinello (2007, p. 61) explica, eles "investigaram o lado obscuro da interação informal nas organizações, as macroestruturas institucionais, os sistemas políticos e a linguagem e o sistema legal.” E o novo institucionalismo que, segundo DiMaggio e Powell (1991, p. 8), compreende uma rejeição dos modelos do ator racional, um interesse em instituições como variáveis independentes, um movimento em direção a explicações cognitivas e culturais, e um interesse em propriedades de unidades supraindividuais de análise que não podem ser reduzido a conjuntos ou consequências diretas de indivíduos. Para Carvalho, Goulart e Vieira (2004) em ambos, a institucionalização limita a racionalidade da organização; o que difere uma da outra são as fontes dessa limitação. Para o velho institucionalismo, os limites eram determinados por grupos de pressão internos à organização. Para o novo, as formas estruturais refletem a busca de estabilidade e de legitimidade face ao ambiente.

No que diz respeito à Teoria Institucional, nota-se que existe pouco consenso sobre a definição de conceitos, mensuração ou métodos. Não possui metodologia de pesquisa 
padronizada, nem métodos específicos. Assim, observa-se que a Teoria Institucional ainda precisa ser institucionalizada (TOLBERT; ZUCKER, 1998).

\subsection{O PROCESSO DE INSTITUCIONALIZAÇÃO NA VISÃO DE TOLBERT E ZUCKER}

Tolbert e Zucker (1998) desenvolveram um modelo em institucionalização é tratada como um processo, descrito pela inter-relação dos conceitos de habitualização, objetificação e sedimentação, conforme figura 1.

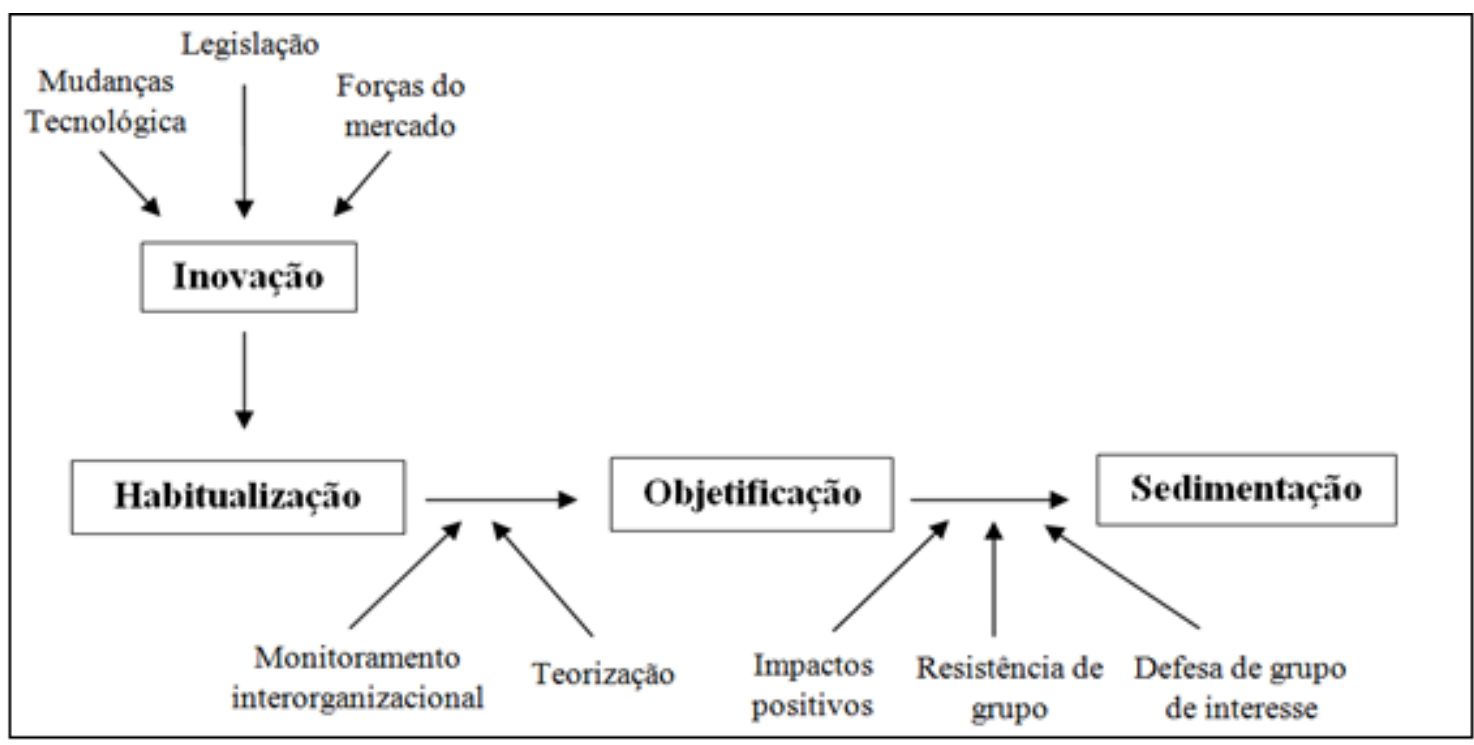

Figura 1 Processo de institucionalização. Fonte: Adaptado de Tolbert e Zucker (1998).

A habitualização, também chamada de estágio pré-institucional, para Tolbert e Zucker (1998), envolve a criação de novos arranjos em resposta a problemas ou incertezas organizacionais. Os fatores relacionados à inovação, propostos pelas autoras, são as mudanças tecnológicas, a legislação e as forças de mercado. Esses arranjos são formalizados em políticas e procedimentos. Soluções que obtém resultados satisfatórios tendem a estimular a imitação como processo de difusão.

A objetificação, ou semi-institucionalização, relaciona-se ao desenvolvimento de certo grau de consenso entre os atores sociais a respeito da relevância da estrutura gerada no estágio anterior. Tal consenso pode surgir da busca de informações (monitoramento organizacional) e evidências colhidas de uma variedade de fontes, como noticiários, observação direta e cotação acionária, e pelo monitoramento dos resultados obtidos por outras organizações (como elas reagiram a situações similares), na busca de avaliar os riscos de adoção da nova estrutura 
(TOLBERT; ZUCKER, 1998; QUINELLO, 2007). Nessa etapa é de grande relevância a fundamentação de ideias (teorização), onde procura-se identificar os fatores relacionados a situação na qual a empresa se encontra e fundamentar a solução proposta.

A institucionalização total envolve a sedimentação. Nesse estágio será relevante a baixa resistência de grupos de oposição, a promoção de apoios contínuos dos grupos de defesa e impactos positivos. Questões importantes também são a propagação da estrutura e a sua perpetuação por um longo período de tempo.

A Teoria Institucional e o processo de institucionalização compreendem que as organizações são influenciadas pelo ambiente. Portanto, para a sua análise faz-se necessário o entendimento de alguns conceitos centrais, dentre eles, o de campo organizacional, que será tratado a seguir.

\subsection{ISOMORFISMO INSTITUCIONAL}

A teoria organizacional tem buscado responder ao questionamento: Porque as organizações são tão semelhantes? A competição acirrada e a necessidade de eficiência levam as organizações a buscarem sua perpetuidade e, muitas vezes, elas vão à busca das melhores práticas de outras organizações, levando a homogeneização.

A questão também tem haver com o nível de estruturação de um campo organizacional. Quanto mais estruturado está o campo, mais surgem forças que levam as organizações a se tornarem mais homogêneas (DIMAGGIO; POWELL, 1983). O conceito que mais se ajusta a esse processo de homogeneização é o do isomorfismo, que pode ser definido como "um processo restritivo que força uma unidade de uma população a se assemelhar a outras unidades que enfrentam o mesmo conjunto de condições ambientais" (DIMAGGIO; POWELL, 1983).

\section{EMPRESA JÚNIOR}

O Movimento Empresa Júnior (MEJ) iniciou-se em 1967, na França, estudantes da ESSEC Business School, conscientes da necessidade de experiências práticas que complementassem a formação acadêmica obtida na faculdade, criaram uma associação sem fins lucrativos, denominada Junior-Entreprise, com o objetivo de complementar a formação teórica adquirida pelos estudantes nos estabelecimentos de ensino superior através de aplicações práticas provenientes do confronto direto com a realidade empresarial. 
Rapidamente a idéia se difundiu no meio acadêmico francês, resultando na criação da Confederação Nacional das Empresas Juniores em 1969, que, em 1980, possuía mais de 100 empresas federadas. Em 1986, surgiram EJs na Bélgica, Espanha, Holanda, Portugal, Itália, Suíça, Alemanha, Hungria e outros países (MATOS, 1997).

No Brasil, conforme Matos (1997), a primeira EJ a ser criada foi a Júnior GV em 1989, na Fundação Getúlio Vargas. Em 1990, a partir da união de sete empresas de São Paulo, foi fundada a Federação das Empresas Juniores do Estado de São Paulo (FEJESP), que teve como objetivo expandir e manter a coerência do MEJ.

Em 2003, foi criada a Confederação Brasileira de Empresas Juniores, a Brasil Júnior (BJ). Conforme o relatório DNA Júnior (2012), realizado pela Brasil Júnior, essa confederação trabalha para fomentar e dar suporte às EJs em todo o Brasil e representá-las para potencializar os resultados da rede de EJs. A BJ é formada atualmente por 14 federações, representando 13 estados e o Distrito Federal. Para uma EJ se federar, é preciso passar por um check-list que abrange: a área legal da EJ, gerenciamento de voluntários e reconhecimento da instituição de ensino superior a ela vinculada. No Ceará, a BJ está representada pela Federação das Empresas Juniores do Estado do Ceará - FEJECE.

Para a Brasil Júnior (2012), EJ é uma associação civil, constituídas por alunos matriculados em cursos de graduação em instituições de ensino superior (IES), com o intuito de realizar projetos e serviços que contribuam para o desenvolvimento do país e de formar profissionais capacitados e comprometidos com esse objetivo. Para Matos (1997) as finalidades das EJs estão voltadas à promoção de atividades de caráter instrutivo e científico de acordo com os preceitos de estudo, pesquisa e extensão universitária, em que, a principal atividade desenvolvida, se dá por forma de projetos de consultoria orientados por docentes.

Conforme Guimarães, Moreira e Baeta (2013), entre objetivos das EJs estão: proporcionar a oportunidade de aplicação prática dos conhecimentos teóricos relacionados à área de formação; desenvolver a capacidade crítica, analítica e empreendedora; intensificar o relacionamento com a instituição de ensino; facilitar o ingresso no mercado de trabalho; contribuir com a sociedade proporcionando um serviço de qualidade a preços acessíveis. Sem, no entanto, ter como objetivo a captação de lucro tanto para os integrantes quanto para a instituição de ensino.

No sentido estrito, conforme Ziliotto e Bert (2012), a EJ proporciona a aplicação prática do conhecimento teórico relativo à área de formação que o aluno tem dentro da 
universidade. Contudo, esse objetivo se amplia consideravelmente em função dos múltiplos desafios que fazem parte dessa experiência, conforme defende Oliveira, Bermúdez e Moraes (2009), a EJ desenvolve características como: criatividade, iniciativa, determinação, pro atividade, liderança, profissionalismo e capacidade de tomada de decisões dinâmicas.

\subsection{ESTUDOS EMPÍRICOS DO CAMPO}

Batista, Bitencourt, Silva et al. (2010) estudaram duas EJs do Rio Grande do Sul e constataram que toda a aprendizagem ocorrida, seja ela formal ou informal, consciente ou inconsciente se passa dentro da EJ, através de troca de conhecimentos entre os membros, e essa é o elemento central para que ocorra aprendizagem. Ainda na ótica da aprendizagem, Vazquez, Silva, Natividade et al. (2012) pesquisaram 449 membros de EJs de quatro regiões brasileiras. Esses autores concluíram que se observa a predominância do conhecimento produzido pela experiência de interação social e análise dos problemas enfrentados nas situações práticas da EJs (enfrentamentos, conflitos, demandas e dificuldades com os quais os alunos lidam para encontrar soluções através dos recursos disponíveis). A pesquisa também mostrou que os alunos reconheceram seu desenvolvimento profissional diferenciado pelo engajamento dessas situações.

Valadão Júnior e Marques (2012) pesquisaram profissionais que foram membros de uma EJ da Universidade Federal de Uberlândia sob a ótica das competências. No estudo verificou-se a predominância das competências técnico-funcionais e comportamentais entre os ex-membros. Em relação às fragilidades, verificou-se baixa construção de competências éticas e políticas.

Bettoni, Silveira, Silva (2011) pesquisaram uma EJ da Universidade Federal do Paraná. Os resultados do estudo apontaram as EJs como propensas às práticas de gestão do conhecimento, devido ao seu caráter experimental, onde erros e acertos trazem conseqüências com menor impacto em relação às outras organizações.

Dalmoro, Trindade, Visentini et al.(2008) entrevistaram 5 membros da Diretoria de uma EJ da Universidade Federal de Santa Maria para investigar a atividade empreendedora nas EJs. Contatou-se que a EJ contribuiu para a ampliação da rede de contatos, desenvolvimento da liderança e da pró-atividade. Porém, nem todos os aspectos relativos ao espírito empreendedor foram incentivados, uma vez que aspectos como inovação, comprometimento e cumprimento de metas não foram verificados integralmente. 
Ziliotto e Bert (2012) defenderam, em seu estudo, o aumento de ações institucionais, por parte das Universidades, bem com o crescimento de publicações referentes à temática, pois, assim, haveria maior conhecimento do tema entre alunos e docentes, fato que fortaleceria o movimento.

\section{METODOLOGIA}

Quanto à abordagem, essa pesquisa se caracteriza por um modelo multimodal. Conforme Sampieri, Collado e Lucio (2013), esse modelo é definido como uma convergência entre os enfoques quantitativo e qualitativo. Tal integração, que também pode ser denominada triangulação, agrega profundidade a um estudo, e, ainda que cheguem a surgir contradições entre os resultados de ambos os enfoques, agrega-se, uma perspectiva mais completa à pesquisa. Essa abordagem vai ao encontro da proposta de Tolbert e Zucker (1998), que defendem a triangulação de dados como método de estudo no processo de institucionalização.

Quanto aos fins, em alinhamento à taxionomia proposta por Sampieri, Collado e Lucio (2013), trata-se de uma pesquisa descritiva, pois esse estudo pretende coletar informações de maneira independente e integrar essas informações para descrever como se manifesta o fenômeno de interesse. Quanto aos meios, é uma pesquisa bibliográfica e de campo, realizada mediante um levantamento junto às EJs.

Para conhecer o campo de estudo do Ceará, foi mapeado, através de pesquisas em sítios na internet das universidades públicas (Universidade Federal do Ceará - UFC, Universidade Estadual do Ceará - UECE e Universidade Estadual Vale do Acaraú - UVA), sites de EJs e entrevista com a vice-presidente da FEJECE, 39 empresas juniores. Dessas, 10 são federadas. Como o objetivo dessa pesquisa é investigar como se dá o processo de institucionalização das EJs das universidades públicas do Ceará e tendo como norte a definição de institucionalização de Selznick (1971, apud QUINELLO, 2007), optou-se por investigar as EJs de universidades públicas do estado do Ceará com 5 anos de existência ou mais, como mostra a tabela 1 .

Quanto à coleta de dados desse estudo, conforme Martins e Theóphilo (2009), foram utilizados: dados primários, questionário e entrevista, que são dados colhidos direto na fonte, e secundários, sítios na internet das instituições, dados já coletados que se encontram organizados em arquivos. 
Tabela 1 Empresas juniores foco do estudo.

\begin{tabular}{|c|c|c|c|c|}
\hline EJ & CRIAÇÃO & CIDADE & IES & CURSO \\
\hline ADM Soluções & 1992 & Fortaleza & UECE & Administração de Empresas \\
\hline Acens & 2008 & Fortaleza & UECE & Ciências da Computação \\
\hline Consultec Jr. & 1999 & Fortaleza & UFC & Arquitetura e Engenharia Civil \\
\hline e-Dea Jr. & 2004 & Fortaleza & UFC & Computação \\
\hline GAUSS & 1999 & Fortaleza & UFC & Estatística \\
\hline Index Consultoria & 2000 & Sobral & UVA & Administração \\
\hline Inova - Empresa Jr. & 2003 & Fortaleza & UFC & $\begin{array}{l}\text { Economia, Administração, Atuária, } \\
\text { Ciências Contábeis, Secretariado e } \\
\text { Finanças. }\end{array}$ \\
\hline Metas Consultoria & 2002 & Fortaleza & UFC & Engenharia Mecânica \\
\hline Politeq Jr. & 2004 & Fortaleza & UFC & Engenharia Química \\
\hline Proativa Jr. & 2002 & Fortaleza & UFC & Engenharia de Produção \\
\hline
\end{tabular}

Fonte: Pesquisa de Campo (2013).

Quanto aos instrumentos de coleta, utilizou-se um questionário, em escala de Likert, e uma entrevista semi-estruturada. Conforme Martins e Theóphilo (2009), a escala de Likert consiste em um conjunto de itens apresentados em forma de afirmações, ante os quais se pede ao sujeito que externe sua reação, escolhendo um dos cinco pontos da escala. Para análise desse instrumento, foram quantificadas as respostas de cada respondente. Os respectivos pesos da escala foram: 0 para discordo totalmente, 1 para concordo, 2 para nem concordo, nem discordo, 3 discordo e 4 para concordo totalmente. Ao final, calculou-se a média geral de cada afirmação das opiniões dos membros da EJ, resultando em um escore que variou de 0 a 4, em que, quanto maior a proximidade com o número 4, maior o índice de concordância em relação à questão. Seguindo o procedimento de pesquisa de Lima (2012) as médias foram segregadas em três níveis: abaixo de 1,5 foi considerado baixo, entre 1,5 e 2,5, moderado e acima de 2,5 alto.

O questionário e o roteiro de entrevista foram estruturados em quatro partes: a primeira correspondia à caracterização do respondente, a segunda à fase de habitualização do processo de institucionalização de Tolbert e Zucker (1998), a terceira à fase de objetificação e a quarta à fase de sedimentação do mesmo modelo. Foram utilizados como base os instrumentos de coleta dos estudos de Lima (2012) e Lima (2008), já validados. O questionário foi enviado para o presidente de cada EJ, que o encaminhou, via e-mail, para os demais membros. Assim, chegou-se a 90 respondentes.

A entrevista semi-estruturada foi realizada com os diretores-presidentes das EJs, conforme a acessibilidade dos mesmos. Conforme Martins e Theóphilo (2009) esse tipo de entrevista é conduzida com uso de roteiro, mas com liberdade de serem acrescentadas novas 
questões pelo entrevistador. As entrevistas foram aplicadas a 5 empresas juniores, a saber: Inova, Politec, Consultec, Gauss e Adm Soluções. O objetivo das entrevistas foi servir de contraponto aos questionários, complementando a compreensão do processo. Cada entrevista durou em média 1 hora, tendo sido gravadas e transcritas. Os dados coletados nas entrevistas foram analisados por meio da técnica análise de conteúdo, que segundo Chizzotti (2011), adota normas sistemáticas de extrair significados temáticos por meio dos elementos simples de um texto. Para isso, é preciso categorizar as respostas da entrevista. Conforme Chizzotti (2011), a eleição de categorias é fundamental para se atingir os objetivos da pesquisa. Nesse estudo, as categorias são a segunda (habitualização), terceira (objetificação) e quarta parte (sedimentação) do roteiro de entrevista que referem-se ao primeiro, segundo e terceiro objetivo, respectivamente, desta pesquisa.

Para a análise, foi utilizado o software Excel. Foram utilizadas técnicas de estatística descritiva básica e análise da entrevista com os presidentes.

\section{APRESENTAÇÃO E ANÁLISE DOS RESULTADOS}

Esta seção traz a análise dos resultados, considerando as três etapas do processo de institucionalização, sob a visão de Tolbert e Zucker. Para as autoras o entendimento desse processo é resultante da identificação das forças causais, fatores determinantes, em cada estágio. Entretanto, alguns destes fatores podem estar presentes em mais de uma fase. Primeiramente, é feita a caracterização dos sujeitos da pesquisa. Em seguida, são analisados aspectos referentes as três fazes do processo de institucionalização.

\subsection{PERFIL DOS PARTICIPANTES}

No que concerne aos respondentes do questionário, a distribuição das 90 respostas entre as EJs se deu confirme a tabela 2:

Tabela 2 Quantidade de respondentes.

\begin{tabular}{lcc}
\hline Empresa Júnior & Qtd. & Percentual \\
\hline Acens & 2 & $2,2 \%$ \\
Adm Soluções & 14 & $15,2 \%$ \\
Consultec Jr. & 14 & $15,2 \%$ \\
e-Dea Jr. & 5 & $5,4 \%$ \\
GAUSS & 13 & $14,1 \%$ \\
Index Consultoria & 2 & $2,2 \%$ \\
Inova & 18 & $19,6 \%$ \\
Politeq & 9 & $9,8 \%$ \\
Proativa & 15 & $16,3 \%$ \\
\hline Total geral & 92 & $100,0 \%$ \\
\hline
\end{tabular}

Fonte: Dados da pesquisa de campo. 
Observa-se que, das 10 empresas que fazem parte da amostra, 9 responderam ao questionário. As universidades analisadas foram a Universidade Estadual do Ceará (UECE), com $17,4 \%$ da amostra, a Universidade Federal do Ceará (UFC), com 80,4\% e a niversidade Estadual Vale do Acaraú (UVA), com 2,2\% da amostra. Essa diferença se explica pela quantidade de EJs em cada universidade, a UECE tem 2 EJs, a UFC tem 7 EJs e a UVA tem 1 EJ entre as EJs foco desse estudo.

Em relação ao sexo, 47,83\% são do sexo feminino e 52,17\% do sexo masculino. No que concerne à idade, a média foi de 20,39 anos, com desvio padrão de 2,79, valor máximo de 35 anos e valor mínimo de 16 anos. Quanto ao tempo de EJ, 39,13\% têm menos de um ano, 40,22\% têm 1 ano, 17,39\% têm 2 anos e 3,26\% têm 3 anos. No que se refere ao cargo ocupado na EJ, $17,39 \%$ são consultores, $54,35 \%$ possuem cargos administrativos e $28,26 \%$ são diretores.

\subsection{PRÉ-INSTITUCIONALIZAÇÃO}

$\mathrm{Na}$ fase inicial, também chamada de habitualização, buscou-se identificar quais foram as mudanças, quem foram os atores envolvidos e os fatores determinantes que levaram a criação das EJs. Os resultados da pesquisa podem ser observados na tabela 3.

Tabela 3 Afirmações acerca do processo inicial de institucionalização.

\begin{tabular}{|c|c|c|c|}
\hline \multicolumn{2}{|c|}{ HABITUALIZAÇÃO } & \multirow{2}{*}{$\frac{\text { Média }}{2,70}$} & \multirow{2}{*}{$\begin{array}{c}\text { Desvio- } \\
\text { padrão } \\
0,75\end{array}$} \\
\hline 1 & Há troca de informações entre as EJs & & \\
\hline 2 & Essa EJ foi criada a partir da iniciativa dos alunos & 3,49 & 0,56 \\
\hline 3 & Essa EJ foi criada para dar maior visibilidade ao curso e a universidade & 2,52 & 0,95 \\
\hline 4 & Essa EJ foi criada para complementar a formação dos alunos & 3,59 & 0,60 \\
\hline 5 & Essa EJ foi criada para aliar teoria e prática & 3,53 & 0,78 \\
\hline 6 & Essa EJ surgiu para ser uma fonte de renda extra para os alunos & 0,45 & 0,65 \\
\hline 7 & Outra EJ serviu de modelo de referência para a formação dessa EJ & 2,40 & 0,79 \\
\hline 8 & $\begin{array}{l}\text { O modelo de EJ da Brasil júnior (FEJECE) serviu como referência para a } \\
\text { formação dessa EJ }\end{array}$ & 1,91 & 1,06 \\
\hline 9 & A Brasil Júnior (FEJECE) incentivou a criação dessa EJ & 1,85 & 1,05 \\
\hline 10 & A Brasil Júnior (FEJECE) apoiou a criação dessa EJ & 2,03 & 1,16 \\
\hline 11 & A estrutura dessa EJ muda bastante & 1,85 & 0,99 \\
\hline 12 & Essa EJ foi criada a partir da iniciativa dos professores & 0,87 & 0,74 \\
\hline 13 & Essa EJ foi criada a partir da iniciativa da universidade & 0,89 & 0,80 \\
\hline 14 & A federação (FEJECE) influencia essa EJ & 2,47 & 1,00 \\
\hline 15 & Essa EJ utiliza as normas e padrões estabelecidos pela Brasil Júnior (FEJECE) & 3,20 & 0,84 \\
\hline 16 & $\begin{array}{l}\text { Essa EJ possui Estatuto, normas e regulamentos aprovados por uma } \\
\text { Assembleia Geral, que devem ser seguidos por todos os associados. }\end{array}$ & 3,63 & 0,53 \\
\hline
\end{tabular}

Fonte: Dados da pesquisa de campo. 
Observa-se que, entre os possíveis atores que tiveram iniciativa na criação da EJ, se sobressaem os alunos, com uma média de 3,49 (item 2). Professores (item 12) e universidade (item 13) ficaram com média 0,87 e 0,89 , respectivamente. Quanto aos motivos da criação da EJ, percebe-se que o principal objetivo foi o de complementar a formação acadêmica, aliando a teoria com à prática, o que está explícito no item 4, com média 3,59 e no item 5, com média 3,53 .

Corroborando com os resultados obtidos na análise quantitativa, a presidente da Consultec afirmou que "a ideia partiu dos alunos mesmo, porque um dos fundadores fazia parte do C.A. e ele queria outra coisa que agregasse mais experiência." Em relação ao objetivo da empresa júnior, o presidente da Inova ressaltou: “o objetivo inicial da EJ, acredito eu, que seria a questão da conciliação, tipo, como em toda empresa júnior, do conhecimento teórico que a gente vê na graduação pra algo mais pratico".

Buscou-se também identificar a influência que a Brasil Júnior, representada no Ceará pela FEJECE, exerce sobre as EJs. Observa-se que, na criação, essa influência é moderada, o que mostra os itens 8,9 e 10, com médias de 1,91; 1,85 e 2,03; respectivamente. Porém, na estruturação das EJs, há uma influência maior, moderada e alta, respectivamente, por parte da federação, o que evidencia os itens 14, com média 2,47 e 15, com média 3,20. Percebe-se que as EJs estão bem estruturadas, conforme o item 16, que apresentou maior média entre os itens dessa seção, 3,63.

Em algumas seções, buscou-se identificar características isomórficas entre as EJs. Em relação ao primeiro estágio, habitualização, observa-se que existiram Ejs que serviram de modelo para a criação de outras, conforme ressaltado pelo item 7 , com média 2,40 e que existem trocas de informações entre elas (item 1, média 2,70). Esse fato é ratificado pela presidente da Consultec:

Eu posso falar o que os fundadores já me falaram, que eles queriam, eles se basearam muito na experiência da ITA Júnior que é a empresa júnior dos cursos do ITA. Eles viam a ITA Júnior como uma grande oportunidade de juntar os conhecimentos que eles adquiriram na faculdade à pratica. (PRESIDENTE CONSULTEC, 2013).

E pelo presidente da Inova:

Há interação, tipo, constantemente. Temos processos de benchmarking com outras empresas juniores [...]. ADM, a Consultec, Proativa, assim as que nós 
temos mais contato. Epro, Acens, mais ou menos, não tanto; com a Gauss também tivemos contato [...]. (PRESIDENTE INOVA, 2013).

No modelo teórico das autoras Tolbert e Zucker (1998), a habitualização está relacionada ao surgimento de novos padrões em resposta às incertezas ou problemas organizacionais. No caso das Ejs, observou-se que o fator preponderante foi a necessidade dos alunos de aliar as teoria à prática.

\subsection{SEMI-INSTITUCIONALIZAÇÃO}

Nessa etapa, chamada de objetificação, faz-se necessário atingir certo grau de consenso entre os atores envolvidos (universidades, professores e alunos) no que diz respeito ao valor da prática, bem como a crescente adoção da nova estrutura e de novos procedimentos com base nesse consenso, a partir monitoramento interorganizacional. Os resultados da pesquisa são apresentados tabela 4 .

Tabela 4 Afirmações acerca da objetificação.

\begin{tabular}{clcc}
\hline OBJETIFICAÇÃO & Média & $\begin{array}{c}\text { Desvio- } \\
\text { padrão }\end{array}$ \\
\hline 1 & Há um consenso entre essa EJ, Brasil Júnior (FEJECE), universidades e & 2,41 & 1,00 \\
professores sobre a atuação e o papel da EJ & A Brasil Júnior (FEJECE) influência no planejamento das atividades dessa EJ & 2,37 & 1,07 \\
3 & Outras EJs influenciam no planejamento das atividades dessa EJ & 1,91 & 0,96 \\
4 & A universidade e os professores influenciam no planejamento das atividades & 1,87 & 1,02 \\
& dessa EJ & 3,17 & 0,70 \\
5 & Há EJs que exercem maiores influências dentro do movimento & 3,05 & 0,62 \\
6 & Existem certos padrões de estruturas que modelam essa EJ & 2,30 & 0,86 \\
7 & Há uma padronização em relação à atuação da EJ na universidade & 1,45 & 0,88 \\
8 & Essa EJ monitora o desempenho de outras EJs. & 2,55 & 0,91 \\
9 & Essa EJ monitora seu mercado de atuação. & 2,91 & 0,83 \\
10 & Essa EJ divulga suas ações através de palestras, eventos e outros. & 1,66 & 0,89 \\
11 & A universidade e os professores buscam e tem interesse em desenvolver a EJ & 2,26 & 0,96 \\
12 & A Brasil Júnior (FEJECE) busca desenvolver também as EJ não federadas & 2,89 & 0,83 \\
13 & A Brasil Júnior (FEJECE) busca desenvolver as EJ federadas & 3,14 & 0,79 \\
\hline & Essa EJ desenvolve parcerias com o objetivo de aumentar seus projetos e & & \\
& perpetuar a estrutura & & \\
\hline
\end{tabular}

Fonte: Dados da pesquisa de campo.

Nota-se um moderado nível de concordância em relação ao consenso dos principais atores das EJs (item 1, média 2,41). No entanto, universidade, professores e outras EJs não exercem grande influência em atividades da EJ, conforme o item 4 , com média de 1,87, item 11, com média de 1,66 e item 3, com média de 1,91. No que concerne a FEJECE, percebe-se 
relativa influência dessa nas atividades das EJs, item 2 média 2,37. Em contraponto ao nível de consenso apresentado pelo questionário, o presidente da Inova afirma que:

\begin{abstract}
Não existe consenso, tipo, por exemplo, tem professores que acham que a empresa júnior é uma coisa, tem professores que acham que é outra, tem alunos que acham que a empresa júnior é uma coisa, tem aluno, tipo, que pensa que a Inova só faz curso, tem aluno que pensa que é só consultoria, tem aluno que pensa que a Inova é um bando de gente que não tá fazendo nada, tem alunos que pensam que a Inova tem os melhores alunos da faculdade, tem aluno que pensa, tipo, opiniões muito distintas, entendeu? Aquela coisa não há um consenso, a própria universidade, às vezes, ela não entende muito bem sobre empresa júnior. (PRESIDENTE DA INOVA, 2013).
\end{abstract}

No entanto, outra EJ acha que os atores reconhecem a importância das mesmas, porém não contribuem de forma ativa para o seu desenvolvimento.

Em contraponto a esse consenso do Departamento inteiro sobre a importância da empresa Junior, eu acho que poderia haver um apoio maior por parte do Departamento, não é? Leia-se os professores para com a Gauss, nós não temos tanto apoio deles, nós temos um professor orientador, mas deixa a desejar esse auxilio dos professores.(PRESIDENTE GAUSS, 2013).

Em relação à disseminação das estruturas, as EJs também buscam divulgar o movimento para que ele possa ser mais reconhecido por todos os atores envolvidos, nota-se isso no item 10, média 2,91(alta). Em muitos casos, essa divulgação ocorre pela participação em eventos organizados por outras instituições.

Em relação ao monitoramento interorganizacional, percebe-se que as EJs buscam monitorar o campo de atuação, item 9 , média 2,55, porém com baixo monitoramento entre as próprias EJS, item 8, média 1,45. Confirmando esse fato, o presidente da Consultec afirma que há uma monitoração em relação a outras EJ's, mas essa não é sistemática: “[...] Não diria exatamente "monitorar", mas a gente sabe sim como elas tem se desenvolvido [...]. [...] dá pra gente meio que comparar como tem sido o crescimento das empresas, mas o de monitorar mesmo, não".

Em relação ao isomorfismo na etapa da objetificação, observa-se que existem EJs que exercem grande influência no movimento (item 5, média 3,17 ). No entanto, essa interferência não tem grande influência no planejamento interno de cada empresa júnior (item 3 , média 1,91). Observa-se também, que existe uma padronização na forma de atuar das Ejs, conforme os item 6, com média 3,05 (alta), o item 2, com média 2,37 (moderada) e o item 7, média 
2,30 (moderada). Essa padronização pode está relacionada às exigências que a federação faz para que as EJs possam ser federadas. Além disso, as EJs partilham boas práticas de gestão, conforme explicitado pelo presidente da Adm Soluções: “[...] o compartilhamento entre as empresas é basicamente das boas práticas de gestão, nós fazemos isso principalmente com a Consultec e a Proativa".

\subsection{INSTITUCIONALIZAÇÃO TOTAL}

Uma prática está institucionalizada quando ela atinge os requisitos da última etapa do processo de institucionalização, a sedimentação. Nessa etapa, percebem-se os impactos positivos, os grupos de resistência e a continuidade da estrutura.

Tabela 5 Afirmações acerca da Sedimentação.

\begin{tabular}{|c|c|c|c|}
\hline \multicolumn{2}{|c|}{ SENDIMENTAÇÃO } & \multirow{2}{*}{$\begin{array}{c}\text { Média } \\
2,97\end{array}$} & \multirow{2}{*}{$\begin{array}{c}\begin{array}{c}\text { Desvio- } \\
\text { padrão }\end{array} \\
1,04\end{array}$} \\
\hline 1 & $\begin{array}{l}\text { A demanda por alunos que querem entrar nessa EJ é maior do que as vagas } \\
\text { existentes }\end{array}$ & & \\
\hline 2 & Essa EJ complementou a formação dos alunos & 3,59 & 0,58 \\
\hline 3 & Essa EJ ajudou a divulgar o curso e a universidade & 3,20 & 0,80 \\
\hline 4 & Essa EJ é bem vista pela universidade & 2,57 & 0,80 \\
\hline 5 & Essa EJ é bem vista pelos professores & 2,32 & 0,81 \\
\hline 6 & $\begin{array}{l}\text { Existem processos específicos nessa EJ que tratam o problema da sucessão de } \\
\text { cargos }\end{array}$ & 2,55 & 1,05 \\
\hline 7 & Essa EJ realiza plenamente suas atividades principais, como consultoria. & 2,97 & 1,00 \\
\hline 8 & $\begin{array}{l}\text { A atuação do SEBRAE e de outros parceiros contribuíram para o melhor } \\
\text { desenvolvimento dessa EJ }\end{array}$ & 1,89 & 1,15 \\
\hline 9 & Essa EJ conseguirá crescer em termos de projetos desenvolvidos & 3,27 & 0,61 \\
\hline 10 & $\begin{array}{l}\text { Essa EJ realiza mais atividades secundárias do que a atividade principal, como } \\
\text { consultorias. }\end{array}$ & 1,95 & 1,08 \\
\hline 11 & $\begin{array}{l}\text { Os alunos entram empolgados nessa EJ, mas com o passar do tempo, ficam } \\
\text { desinteressados }\end{array}$ & 1,89 & 0,93 \\
\hline 12 & A falta de projetos de consultoria desmotiva os alunos que entram nessa EJ & 1,77 & 1,18 \\
\hline 13 & Essa EJ monitora o desempenho de suas atividades & 3,23 & 0,73 \\
\hline 14 & Essa EJ encontra algumas barreiras a sua atuação & 2,87 & 0,90 \\
\hline 15 & $\begin{array}{l}\text { Houve cargos vagos nessa EJ a ponto de não haver perspectivas de } \\
\text { continuidade da EJ }\end{array}$ & 1,16 & 1,06 \\
\hline
\end{tabular}

Fonte: Dados da pesquisa de campo.

Observa-se que as EJ's monitoram suas atividades (item 13, média 3,23), são bem vistas pela universidade e professores (item 4, média 2,57 e item 5, média 2,32) e trazem inúmeros benefícios aos atores envolvidos, dentre eles: complementa a formação dos alunos (item 2 , média 3,59) e contribui para a divulgação do curso e da universidade (item 3, média 3,20). 
No que diz respeito aos grupos de resistência, não se observa um grupo específico que vá de encontro às EJs. No entanto, as EJs encontram barreiras para a sua atuação (item 14, média 2,87).

Existem dificuldades para atuar. Já houveram momentos em que a quantidade de clientes não era satisfatória, tínhamos poucos clientes e ir atrás desses clientes é uma atividade que não é trivial dentro da nossa empresa, [...] teve um período em que a Gauss esteve sem professororientador, isso também foi um empecilho para as nossas atividades. Porque surgem certas atividades que nós poderíamos ter pegado, ter participado, que foram descartadas, foi negado ao cliente, por falta de professor-orientador, então esse foi um empecilho. (PRESIDENTE GAUSS, 2013).

Em relação à perspectiva de continuidade, observa-se que as EJs continuarão a atuarem no cenário das universidades públicas do Ceará. Isso é notório pela baixa média encontrada nos itens 11 (média 1,89), 12 (média 1,77) e 15 (média 1,16). Soma-se a isso, o fato de a demanda dos alunos para ingressarem na EJ é alta (item 1, média 2,97) e os projetos tendem a aumentar (item 9, média 3,27).

Em relação ao item 15, deve-se destacar que os dados do questionário divergem das entrevistas dos presidentes. O presidente da Consultec afirmou que "Em 2010, eu acho, tinha uma pessoa, só tinha o presidente". Na mesma linha, o presidente da Inova falou que "[...] acaba que chegou um momento que ficaram só duas pessoas e elas não tinham essa preparação pra assumir aquilo [...]”. O presidente da Gauss afirmou que o quadro foi ainda mais grave em sua empresa: “[...] uma antiga presidente que a gente mantém certo contato, eles pensaram realmente em fechar a empresa Junior devido justamente à falta de membros. [...] Eles estavam desmotivados, com poucos clientes, [...] mas de uns quatro anos pra cá, isso não tem ocorrido."

Para minimizar esse problema, conforme as entrevistas dos presidentes, as EJs desenvolveram um processo específico de seleção para a sucessão de cargos, em que os novos membros (trainees) são treinados para assumir cargos de gerência ou diretoria. Os resultados dos questionários confirmam esse fato, o item 6 apresentou média de 2,55.

Essa seção buscou analisar o processo de institucionalização das empresas juniores das universidades públicas do Ceará, à luz do modelo de Tolbert e Zucker (1998). A seguir serão apresentadas as conclusões do estudo. 


\section{CONCLUSÃO}

Esse trabalho se propôs a investigar o processo de institucionalização das EJs das universidades públicas do Ceará. Para isso, buscou-se identificar os principais fatores que motivaram a criação e desenvolvimento desse movimento dentro das universidades analisadas.

A atividade de extensão empresa júnior é de grande importância para o desenvolvimento dos alunos nas universidades, como corroboram os resultados deste estudo, ela proporciona o aprimoramento de competência e uma visão da relação entre a teoria e a prática antes mesmo de terminarem o curso.

Em relação ao primeiro objetivo específico (identificar os principais fatores que motivaram o surgimento e desenvolvimento das EJs das universidades públicas do Ceará), constatou-se que a EJ foi criada por iniciativa dos alunos e um dos principais motivos foi a tentativa de aliar a teoria à prática. Assim, o pressuposto inicial de que o principal fator que motivou o surgimento e desenvolvimento das EJs das universidades públicas do Ceará foi a necessidade de aliar a teoria à prática foi confirmado.

Quanto ao segundo objetivo específico, verificou-se que os principais atores envolvidos são os alunos, e são eles que desenvolvem diretamente o movimento. Eles contam com a ajuda de professores, no entanto ainda de forma precária. Os resultados confirmam o pressuposto: os principais atores sociais no processo de institucionalização das EJs das universidades públicas do Ceará são os alunos.

No tocante ao terceiro objetivo específico, concluiu-se que a EJ complementa a formação dos alunos e contribui para a divulgação do curso e da universidade, além de desenvolver as competências dos alunos. Também foi verificado que não existe um grupo específico de resistência, mas as Ejs encontram barreiras à sua atuação, tais como estrutura, rotatividade e falta de auxílio de professores na supervisão de consultorias. Os alunos foram confirmados como o principal grupo de interesse. Em relação à perspectiva de continuidade, uma das maiores dificuldades encontradas é a rotatividade, que faz com que haja cargos não ocupados. No entanto, um processo seletivo mais sólido e a capacitação dos próprios membros tem feito com que essa questão seja atenuada, assim, os integrantes das EJs acreditam na sua perpetuidade. Os resultados estão alinhados com o terceiro pressuposto (em relação aos impactos positivos, percebe-se que a maior contribuição das EJs é o aumento da aprendizagem interdisciplinar voltada para o mercado, não há grupos de resistência e os 
principais interessados são os alunos, em relação à perspectiva de continuidade, esse é um dos principais problemas devido ao alto grau de rotatividade dos membros das EJs).

No que diz respeito ao quarto objetivo, observou-se que as EJs estão entre as fases de objetificação e sedimentação, fato que nega o pressuposto de que as EJs estão no estágio de sedimentação.

Quanto ao quinto objetivo, é notório que as EJs se espelharam em outras para a sua criação e que elas compartilham práticas de gestão, principalmente em eventos do MEJ. Elas também são padronizadas, isso se dá em função das exigências da federação. $O$ último pressuposto de que as características isomórficas estão relacionadas ao compartilhamento das boas práticas de gestão, foi, assim, confirmado.

Os fatores limitadores encontrados na pesquisa foram a não resposta dos questionários por parte de todas as EJs que compõem a amostra. E o fato de não ser possível a realização das entrevistas com as 10 EJs, devido à indisponibilidade dos presidentes. No entanto, os dados colhidos foram suficientes para uma análise representativa do objeto de estudo. Outro limitador é o fato de as fases do modelo proposto por Tolbert e Zucker (1998) não são estanques, ou seja, não há uma clara delimitação de cada fase do processo.

Futuros trabalhos poderão analisar e comparar o processo de institucionalização em das EJs em universidades públicas e privadas. Outra sugestão de pesquisa é que esse estudo pode ser aplicado nos demais estados brasileiros.

\section{REFERÊNCIAS}

BATISTA, M. K.; BITENCOURT, B. M.; SILVA, F; M.; RUAS, R. L. Empresa júnior: onde a moeda de troca é o conhecimento. In: ENCONTRO DA ASSOCIAÇÃO NACIONAL DE PÓS-GRADUAÇÃO E PESQUISA EM ADMINISTRAÇÃO-ENANPAD, XXXIV, 2010, Rio de Janeiro-RJ. Anais... Rio de Janeiro: ANPAD, 2010.

BETTONI, E. M.; SILVEIRA, E. X.; SILVA, H. F. N. Práticas gerenciais em gestão do conhecimento: um estudo da aplicação em empresas juniores. Informação \& Informação, v. 16 , n. 1, p. 72-87, 2011.

BRASIL JÚNIOR. Censo e Identidade. Disponível em: <brasiljunior.org.br/site/arquivos/download/24>. Acessado em: 16 de maio de 2013.

Conselho Nacional de Empresa Júnior. Disponível em:

$<$ brasiljunior.org.br/site/arquivos/download/2>. Acessado em: 16 de maio de 2013.

DNA JR. Disponível em: < brasiljunior.org.br/site/arquivos/download/34> . Acessado em: 16 de maio de 2013. 
BERGER, P. L; LUCKMAN, T. A construção social da realidade. 16 ed. Petrópolis: Vozes, 1998.

CARVALHO, C. A.; GOULART, S.; VIEIRA, M. M. F. A inflexão conservadora na trajetória histórica da teoria institucional. In: ENCONTRO ANUAL DA ANPAD, 28., 2004, Curitiba. Anais ... Rio de Janeiro: ANPAD, 2004. 1 CD-ROM.

COSTA, A. M.; LIMA, D. M. C.; BARROS, D. F.; MARTINS, P. E. M. Alinhando Discursos: As Práticas Empreendedoras das Empresas Juniores à Luz da New Public Management. In: ENCONTRO DE ADMINISTRAÇÃO PÚBLICA E GOVERNANÇA, 2010, Vitória-ES. Anais... Rio de Janeiro: ENAPAG, 2010.

CHIZZOTTI, Antonio. Pesquisa qualitativa em ciências humanas e sociais. 4 ed. Petrópolis, RJ: Vozes, 2011.

CRESWELL, John. Projeto de pesquisa: métodos qualitativo e quantitativo. 3 ed., Porto Alegre: Artmed, 2010.

DALMORO, M.; TRINDADE, L. L.; VISENTINI, M. S.; LOBLER, M. L. As Empresas Juniores como Fomentadoras do Espírito Empreendedor em Instituições de Ensino Superior. In: SIMPOSIO DE GESTÃO DA INOVAÇÃO TECNOLÓGICA, XXV, 2008, Brasília-DF. Anais... Rio de Janeiro:SIMPÓSIO, 2008.

DIMAGGIO, P. J.; POWELL, W. W. Introduction. In: POWELL, W. W.; DIMAGGIO, P. J. (Eds.). The new institutionalism in organizational analysis. Chicago: The University of Chicago Press, 1991. p. 1-38.

. The iron cage revisited: institutional isomorphism and collective rationality in organizational fields. American Sociological Review, v.48, p.147-160, 1983.

GUIMARÃES, T. de A.; MOREIRA, N.C.; BAETA, O.V.. A negociação com clientes em empresas juniores da Universidade Federal de Viçosa - Campus Viçosa/MG. Revista de Administração da UNIPEP, v.11, n.1, p.81-103, 2013.

JEZINE, E. As Práticas Curriculares e a Extensão Universitária. In: Anais do $2^{\circ}$ Congresso Brasileiro de Extensão Universitária. Minas Gerais: UFMG, Gestão 12, 2004, Gestão 12.

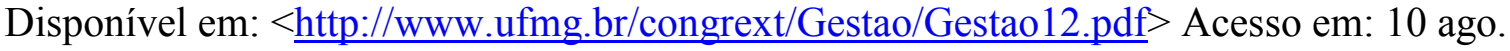
2013.

LIMA, Teresa C.A. A institucionalização das práticas de responsabilidade social: um estudo de caso na Companhia de Água e Esgoto do Ceará. Fortaleza, 2008. 168f. Dissertação (Mestrado em Administração). - Faculdade de Economia, Administração, Atuária e Contabilidade, Universidade Federal do Ceará, Fortaleza, 2008.

LIMA, Bruno C. C. Economia criativa no Ceará: um estudo da institucionalização do campo do humor, 2012. 195p. Dissertação (Mestrado em Administração). - Faculdade de Economia, Administração, Atuária e Contabilidade, Universidade Federal do Ceará, Fortaleza, 2008. 
LIMA, T. F.; CANTAROTTI, A. A formação e a construção de competências para a atuação do profissional de secretariado executivo: um estudo de caso de uma empresa júnior. Revista de gestão e secretariado, v. 1, n. 2, p. 94-122, 2010.

MACHADO-DA-SILVA, Clóris L.; GONÇALVES, Sandro, A. Nova técnica: a teoria institucional. In: CALDAS, M.; FACHIN, R.; FISCHER, T. (Org.). Handbook de Estudos Organizacionais: modelos de análise e novas questões em estudos organizacionais. São Paulo: Atlas, 1999.v.1.

MATOS, Franco de. A empresa júnior no Brasil e no mundo: o conceito, o funcionamento e as tendências do movimento EJ. São Paulo: Martin Claret LTDA, 1997.

MARTINS, Gilberto de Andrade; THEÓPHILO, Carlos Renato. Metodologia da investigação científica para ciências sociais aplicadas. São Paulo: Atlas, 2009.

NORTH, DOUGLAS. Institutions, institutional change and economic performance. New York: Cambridge University Press, 1990.

MEISTER, J.C. Educação corporativa: a gestão do capital intelectual através das universidades corporativas. São Paulo: Makron Books. 1999.

MEYER, John; ROWAN, Brian. Institucionalized organizations: formal structure as myth and ceremony. American Journal of Sociology, v.83, n.2, p.341-63, 1977.

OCANÃ, W. R. V.; CARVALHO, R. da Silva. Formação e estruturação do campo organizacional da indústria pesqueira em Callao, Peru. Revista Eletrônica de Ciência Administrativa, v. 5, n. 2, p. 1, 2006.

OLIVEIRA, Fernanda Coelho; BERMÚDEZ, Luís Afonso; MORAES, Ednalva Fernandes Costa de. Importância da Empresa Júnior para o desenvolvimento profissional dos universitários. XIX Seminário Nacional de Parques Tecnológicos e Incubadoras de Empresas. Florianópolis, SC, 26 a 30 out. 2009. Disponível em: $<$ http://www.redetec.org.br/publique/media/p_14.pdf $>$. Acessado em: 02 de junho de 2013.

QUINELLO, Robson. A teoria institucional aplicada à administração. São Paulo: Novatec, 2007.

ROESCH, Sylvia Azevedo. Projetos de estágio e de pesquisa em administração: guia para estágios, trabalhos de conclusão, dissertações e estudos de caso. 3. ed., São Paulo: Atlas, 2006.

SAMPIERI, R. H.; COLLADO, C. F.; LUCIO, P. B. Metodologia de pesquisa. 5 ed.,São Paulo: McGraw-Hill, 2013.

SANTOS, M. P. Extensão universitária: espaço de aprendizagem profissional e suas relações com o ensino e a pesquisa na educação superior. Conexão UEPG, v.8 , n.2, p. 154-163, 2012. 
TOLBERT, P. S.; ZUCKER, L. G. Institutional sources of change in the formal structure of organizations: the diffusion of civil service reform, 1880-1935. Administrative Science Quarterly, v.28, p.22-39, 1983.

A Institucionalização da Teoria Institucional. In: HARDY, C; CLEGG, S.; NORD, W. (Orgs.); CALDAS, M.; FACHIN, R.; FISCHER, T. (Orgs.brasileiros). Handbook de Estudos Organizacionais: modelos de análise e novas questões em estudos organizacionais. São Paulo: Atlas, 1998. v. 1, p.196-219.

VALADÃO JÚNIOR, V. M.; MARQUES, R. A. C. Empresa Júnior: Espaço Para Construção de Competências. In: ENANPAD, XXXVI, 2012, Rio de Janeiro-RJ. Anais... Rio de Janeiro: ANPAD, 2012.

VAZQUEZ, A. C. S.; SILVA, F. M.; NATIVIDADE, J. C.; RUAS, R. L. Aprendizagem em Situações Práticas: A Formação Profissional na Experiência de Alunos em Empresas Juniores no Brasil. In: ENANPAD, XXXVI, 2012, Rio de Janeiro-RJ. Anais... Rio de Janeiro: ANPAD, 2012.

ZILIOTTO, D. M; BERTI, A. R. A aprendizagem do aluno inserido em empresa júnior. Revista Conexão da UEPG, v. 8, n. 2, p. 210-217, 2012. 